\title{
Reflexões sobre gênero e etnicidade nos cenários e repertórios de participação política no Vaupés colombiano
}

Reflections on gender and ethnicity in the scenarios and repertoires of political participation in the Colombian Vaupés

María Rossi Idárraga*

* Museu Nacional/Universidade Federal de Rio de Janeiro - Rio de Janeiro, RJ, Brasil Em pós-doutoramento (bolsista PNPD/Capes) paramaria@gmail.com https://orcid.org/0000-0002-6804-3838 


\title{
Resumo
}

O artigo propõe uma leitura do movimento político indígena no Vaupés, considerando a década de 1970 como ponto de partida e chegando até meados da década de 2010, atentando para o processo de configuração da primeira organização regional, seguindo com a titulação do resguardo e passando pelas mudanças trazidas com a Constituição política da Colômbia em 1991. A análise chama a atenção para articulação entre as mudanças legais e administrativas do território e as mudanças nas relações de gênero nesse processo, salientando como alguns espaços e práticas da política regional vão se constituindo e consolidando como masculinas, enquanto que outros significantes e repertórios, considerados masculinos em termos de pertencimento étnico, passam a estar disponíveis para o exercício político das mulheres. Assim, várias representações de etnicidade feminina são acionadas em foros políticos, e o território cobra valor para além da origem ancestral, enquanto sustento dos direitos e da organização política.

Palavras-chave: resguardos indígenas; participação política; gênero e etnicidade; Vaupés.

\begin{abstract}
This paper proposes a study of the indigenous political movement in the Vaupés, considering the 1970s as a starting point and reaching the middle of the 2010s, regarding the process of configuration of the first regional organization, following the titling of the indigenous land and undergoing the changes brought by the political constitution of Colombia in 1991. The analysis focuses on the articulation between the legal and administrative changes in the territory and the changes in gender relations in this process, highlighting how some spaces and practices of regional policy are being constituted and consolidated as masculine, although other signifiers and repertoires, considered masculine in terms of ethnic belonging, are now available for the political exercise of women. Thus, several representations of the feminine ethnicity are made in political forums, while the territory assumes meaning beyond the ancestral origin, as a support of rights and political organization.
\end{abstract}

Keywords: indigenous lands; political participation; gender and ethnicity; Vaupés. 
A participação política dos povos indígenas na Colômbia pode ser lida a partir da Constituição de 1991 (República de Colombia, 1991), que reconhece direitos e estabelece várias das estruturas administrativas sob as quais funcionam os espaços de governo indígena, de participação em decisões políticas e administrativas e de consulta. Mas um dos elementos estruturantes da autonomia indígena, base para o reconhecimento de direitos e a aplicação de várias das políticas públicas, está nos resguardos indígenas, territórios de propriedade coletiva, cuja origem data de tempos coloniais e que foi regulamentada na década de 1960. Muitos dos resguardos atuais foram titulados antes da Constituição de 1991, como fruto de reivindicações e lutas dos povos através de diferentes organizações e alianças. Portanto, ao estudar a participação política dos povos indígenas resulta pertinente ver a Constituição não só como marco que abre oportunidades, mas como evento marcante que gera mudanças em processos já existentes, e se articula em conjuntos de práticas e relações locais e regionais, para procurar entender como as estruturas de participação política e administração de territórios indígenas são diferentes em cada região atentando para processos históricos de organização política e de mudanças nas formas de organização, representação e participação.

As relações entre gênero e etnicidade também devem ser lidas historicamente, como já argumentou Joan Scott (1988), para entender como são construídas, narradas e legitimadas e como mudam historicamente. Recuperando também a utilidade de gênero como categoria de análise para pensar as formas de significar as relações de poder, chamo a atenção para como essa configuração de gênero, etnicidade e participação política faz parte do processo histórico no qual essas relações e suas representações vão consolidando umas formas e não outras.

Com essas premissas, apresento algumas reflexões sobre mudanças no movimento indígena e na participação política no departamento do Vaupés, começando na década de 1970 com a criação do Conselho Regional Indígena do Vaupés (Criva), passando pela titulação dos resguardos no departamento, chegando até meados da década de 2010. A análise segue dois eixos; primeiro, as relações entre o resguardo enquanto figura legal e administrativa que passou por várias mudanças, e algumas das suas consequências no cenário da política indígena, e, segundo, as reconfigurações nas relações de gênero nos espaços políticos. A conexão entre os dois eixos está no passo do território ancestral 
e a representatividade étnica como repertórios masculinos, para a participação política pautada em direitos e no resguardo enquanto território reconhecido, como condições suscetíveis de serem também repertórios femininos.

Os espaços de participação política indígena no Vaupés foram construídos em relacionamentos intensos com a Igreja católica, tanto na educação das pessoas que vão ser protagonistas nesses espaços como no processo de criação do Criva, em 1973. Nas modificações dessa cena da participação política etnicamente diferenciada, nas décadas de 1980 e 1990, esses espaços de representação, participação e gestão política se ampliam, e vão se masculinizando, reduzindo a participação das mulheres e dando visibilidade a discursos masculinos de etnicidade e pertencimento.

Depois desse momento, marcado pela aplicação das mudanças estabelecidas na Constituição política de 1991, a descentralização da administração nacional e a inclusão de novas diretrizes na participação e representação da população, entram em cena outros atores e pautas. Mas na década de 1990 a participação política estava enfraquecida pela violência armada no departamento, assim que é mais para o início dos anos 2000 quando as organizações e os espaços de participação recuperam fôlego. A configuração das organizações e das relações com espaços de cooperação internacional nesse momento fazem das mulheres indígenas um tema ou um assunto político, e nesse movimento tratam as mudanças recentes nas relações de gênero na participação política como fatos já estabelecidos, naturalizando-os. Nesse cenário, as mulheres lidam com as limitações e oportunidades que ser tema de política e potenciais agentes políticos lhes oferecem, e utilizam esses espaços de participação como possibilidades de mobilidade social.

As reflexões que se apresentam neste artigo vão até meados dos anos 2010, já que as mudanças ocorridas depois, para a criação de um Conselho Maior Indígena do Vaupés, ${ }^{1}$ não serão incluídas. Os dados da pesquisa de campo utilizados são decorrentes de períodos entre 2013 e 2015 e de uma visita à região em 2018. Trabalhei no Vaupés entre 2006 e 2009. Posteriormente, estive na região como pesquisadora em três períodos diferentes, entre agosto de 2013

1 Em 2018 foi publicado pelo Ministério del Interior o decreto 632 (República de Colombia, 2018), que regulamentaria os conselhos indígenas nos departamentos de Amazonas, Guainía e Vaupés. 
e janeiro de 2015, na cidade de Mitú e nas imediações, especificamente em comunidades localizadas na estrada Mitú-Montfort, e na comunidade de Pituna, no médio igarapé Cuduyarí, todas elas dentro do Resguardo Vaupés (ver Figura 1).
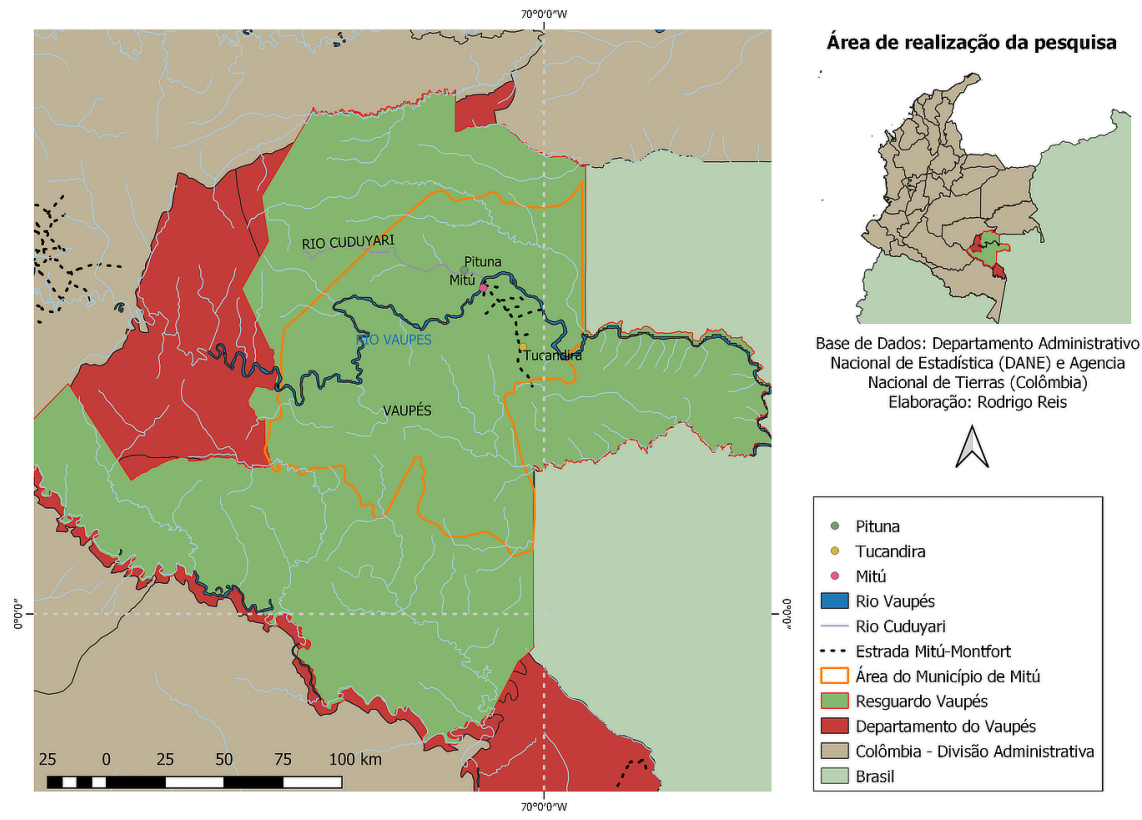

Figura 1. Mapa com a área de realização da pesquisa.

Comecei visitando mulheres que já conhecia, que fizeram parte das organizações indígenas, que me apresentaram outras mulheres ou forneceram indicações necessárias para encontrá-las. Progressivamente fui indicada para acompanhar eventos, nos quais encontrei outras mulheres que não faziam parte das organizações, mas que participavam dessas atividades. Compartilhei com mulheres das organizações do resguardo, do Criva, capitãs de bairros e comunidades, professoras, pessoas próximas das organizações e interessadas na participação num sentido amplo, e realizei entrevistas de tipo biográfico com várias delas. 


\section{Contexto regional}

O departamento do Vaupés está localizado na Amazônia colombiana, na fronteira com o Brasil. Tem uma extensão de $54.135 \mathrm{~km}^{2}$, e é reconhecido nacionalmente como o território com maior diversidade de povos indígenas e de línguas. Segundo Cabrera Becerra (2010), na região do rio Vaupés e do alto rio Negro na Colômbia e no Brasil há seis famílias linguísticas, ${ }^{2}$ cada uma reunindo vários grupos linguísticos. Somam 29 filiações linguísticas, entre as quais três não estariam presentes na Colômbia, logo, há 26 filiações linguísticas no Vaupés colombiano (Cabrera Becerra, 2010, p. 368).

Segundo Correa (1996, p. 12), os grupos do que é chamado complexo sociocultural do Vaupés se distinguem pelo seu nome, a elaboração de certas artes, a propriedade de certos cultivos, a ascendência ancestral, a propriedade sobre elementos ritualísticos, a história mítica de sua origem e deslocamento primordial, seus próprios lugares de nascimento, o território estabelecido desde tempos ancestrais e a singularidade linguística. A língua própria, marcador de identidade fundamental, é herdada pela via paterna, assim como as prescrições de casamento, que devem ser com membros de outro grupo, frequentemente falantes de outra língua. Por conseguinte, um indivíduo aprende desde criança a sua língua, que é a paterna, e uma segunda língua, a da sua mãe (Correa, 1987).

De acordo com Christine Hugh-Jones (2013) a estrutura social poderia ser resumida assim: a exogamia é a lei fundamental de casamento; a descendência é patrilinear, a residência é patrilocal e o matrimônio, virilocal. Quer dizer, a construção de grupos ou coletividades, o pertencimento a eles e a moradia são pautadas por vias masculinas. Com respeito à residência, Jackson (1976, p. 69) aponta que, ainda que as normas sejam de patrilocalidade, por diversos motivos o que acontece é que uma porção significativa de famílias não vai residir onde supostamente deveria.

Nessas coletividades, as mulheres indígenas ocupam posições diferentes das dos homens, principalmente porque elas não transmitem o pertencimento às coletividades que operam desde o núcleo familiar e que são identitárias: 0 grupo linguístico, a etnia, o clã, a especialização, o conhecimento xamânico,

2 A família linguística Tukano oriental (14 grupos), a Tukano médio (1 grupo), a Tukano não classificado (4 grupos), a Arawak (6 grupos), a Maku-Puinave (3 grupos) e a Carib (1 grupo). 
a origem mítica. Elas não transmitem nem ensinam isso, e seus filhos vão se identificar com outra etnia, outro clã, outra língua, e outros saberes.

Outro elemento de especial interesse é que elas têm uma relação diferente com o território: ainda que seu lugar de origem, enquanto membros de um povo, seja o mesmo que o dos homens, e ainda que seu local de nascimento seja tão determinante nas suas vidas quanto para eles, elas estão destinadas a ir embora. O conhecimento sobre seu território de origem é masculino, sua transmissão também. Não corresponde a elas narrar, conservar, nem cuidar desses lugares, elas vão morar na terra de outros, com as famílias de outros, e cuidarão desses lugares alheios. Seus filhos farão parte desses outros grupos, seu trabalho será para esses grupos. Em consequência, para as mulheres identidade, pertencimento e convivência são diferentes. Como descrevo em outro lugar, tal compreensão do pertencimento étnico e das alianças matrimoniais localiza, de várias formas, os limites dos grupos étnicos na circulação das mulheres, que, ao serem estrangeiras na sua família conjugal e ausentes na sua família paterna, levam esses limites à intimidade do cotidiano (Rossi, 2016, p. 371).

Na sua participação num foro político em termos de pertencimento étnico, nos deparamos com os seguintes paradoxos: ao falar em nome do seu grupo, em defesa do seu território originário, e do conhecimento ancestral da sua família paterna, não estariam falando em nome do grupo de seus filhos e seu marido e não estariam defendendo o território em que residem. Já pensando em articular representação com conhecimento ancestral (sobre suas origens), cabe insistir em que este não é tradicionalmente ensinado às mulheres, portanto não se espera que elas sejam suas transmissoras, então aquilo seria pouco provável e inadequado. Agora, se elas fossem representar os interesses de seu núcleo familiar mais próximo (marido e filhos) ou da comunidade na qual residem, se deparariam advogando por interesses de outro povo, defendendo outros territórios, e tendo que aceitar o seu desconhecimento sobre saberes ancestrais, ou, quando menos, a impertinência de sua fala nesses domínios.

Mas, no Vaupés, a participação política não se desprende, sem mais, das relações identitárias entre os grupos indígenas. Decorre de processos históricos e relações mais amplas, envolvendo outros atores, desafios e oportunidades. A mobilização indígena não tomou como ponto de partida as identificações étnicas específicas, nem as tensões entre os grupos diferenciados. Tomou como eixo a diferenciação, num sentido amplo, diante da população colombiana 
em termos gerais, na oposição indígenas-não indígenas, junto com a reivindicação da propriedade coletiva do território, dando origem a um Conselho Regional Indígena, nesses termos amplos de identificação territorial.

Desde seu início, o Conselho Regional Indígena teve como interlocutor principal o Estado colombiano. Abordo Estado aqui não como um objeto empírico dado a priori, mas sim como um conjunto de práticas e processos, e seus efeitos (Trouillot, 2001, p. 126). Desse modo, estou me referindo a uma realidade sociológica e empiricamente observável em instituições, agentes, normas e procedimentos, que constituem localizações sociais variadas (Teixeira; Souza Lima, 2010, p. 79). E entendendo Estados como "unidades sociopolíticas, institucionalidades e fronteiras que moldam e afetam tanto ordens macropolíticas, quanto rotinas burocráticas que nos regem a todos cotidianamente", seguindo Vianna e Lowenkron (2017, p. 2). Compartilho com estas autoras que tanto gênero quanto Estado são processuais e não homogêneos, assim como seria etnicidade. Desse modo, ao apresentar essas reflexões sobre gênero, etnicidade e participação política, recupero o que elas expressam sobre como o Estado também se faz na "gestão de imagens sobre o feminino e, através delas, da reconfiguração de imagens de nação" (Vianna; Lowenkron, 2017, p. 47), ao que neste caso vale a pena acrescentar imagens sobre a etnicidade feminina especificamente.

\section{Algumas considerações sobre o processo de construção de um espaço de participação política}

No dia 3 de dezembro de 1973 se realizou em Mitú, capital do Vaupés, a maior reunião de indígenas que tinha acontecido na cidade. Foi convocada por várias pessoas, principalmente professores, motivados por membros da prefeitura apostólica de Mitú. Aconteceu dentro da escola María Reina e, segundo relatos de vários participantes, teve presença de quase 1500 pessoas, maiormente capitães das comunidades, mas também famílias completas. Constitui o marco de referência para a mobilização e é narrada pelos participantes como um momento marcado pelo interesse coletivo em se organizar e atuar em função de uma coletividade, entendida como geral. Esse ponto vai pesar em todos os relatos e vai ser lembrado com nostalgia e como parâmetro moral: ninguém recebeu dinheiro por estar lá, ninguém recebeu apoio de nenhum tipo (gasolina, 
motor, alimentação, o que for). As pessoas foram por seus próprios meios, em suas canoas ou andando, levaram sua própria comida, algumas foram com toda a família e algumas levaram vários dias para chegar lá.

Nessa reunião se formou o Conselho Regional Indígena do Vaupés - Criva e ela ficou registrada como seu primeiro congresso. Nos documentos a que tive acesso aparecem sete delegações do departamento, ${ }^{3}$ com 81 participantes, dos quais cinco são mulheres (Santacruz, 1985, p. 65-68). Além do apoio da prefeitura apostólica do Vaupés, sua fundação se faz em diálogo com membros do recém-fundado Conselho Regional Indígena do Cauca (Cric) (Jackson, 2001, p. 7), no início do movimento indígena colombiano atual.

Segundo conversas com Jesús Santacruz, um dos participantes dessa reunião e primeiro presidente do Criva, a ideia de uma organização para defender os interesses dos povos indígenas do Vaupés surgiu de monsenhor Belarmino Correa e de Manuel Valencia Cano, sacerdotes preocupados com os indígenas da região. Todas as pessoas com as quais falei e os documentos consultados coincidem nesse ponto. Começou com uma reunião de professores para conversar sobre o assunto, e depois os professores foram para diferentes comunidades no departamento a divulgar a ideia e chamar os capitães para a reunião. Os temas tratados nela, como preocupações ou pontos sobre os quais a organização deveria trabalhar, foram: a estrada Transamazônica, que estava sendo proposta pelo Brasil, que até agora não foi concluída, a saúde, a educação e o território.

Sob a bandeira de melhorar as condições de vida dos indígenas do Vaupés; o Criva começou com a solicitação de saída da região do Instituto Linguístico de Verão e logo tomou distância da Igreja católica (Jackson, 2001, p. 8). Em seguida trabalharam pela declaração do Resguardo Vaupés, para garantir a propriedade do território, e, ao consegui-la, em 1982, o Criva passou a ser a autoridade que o representava, mas continuou sendo a organização que representava aos indígenas do departamento em geral, quer dizer, além dos limites do resguardo. Sua posição como organização estava orientada a trabalhar sobre o território, a autonomia e a unidade (Salazar; Gutiérrez; Franco, 2006, p. 59).

3 Delegação do igarapé Yi (3 pessoas), Mitú Cachivera (11 pessoas), igarapé Cuduyarí (17 pessoas), Querarí (17 pessoas), Puerto Asís (5 pessoas), Papurí e Paca (14 pessoas), e Villa Fátima (14 pessoas). 
Junto com o Conselho Regional Indígena do Cauca, e com representantes de outros povos e organizações, fundaram em 1982 a Organização Indígena de Colômbia (Onic). Progressivamente na Onic o protagonismo foi das organizações andinas, mas o Criva continuou atuando nacional e regionalmente, e em 1995 organizou em Mitú o Primeiro Congresso dos Povos Indígenas da Amazônia, no qual criaram a Organização dos Povos Indígenas da Amazônia Colombiana (Opiac), que continua sendo interlocutora do Criva e da Onic e, junto com eles, dialoga com entidades estatais, internacionais e não governamentais na região.

Já na década de 1990, com a nova Constituição e a descentralização nacional da gestão do território, o Criva recebe o direito da gestão territorial, administrativa e financeira do resguardo, o que lhe dá meios econômicos e políticos para exercer a autonomia, ao menos parcialmente. No entanto, para Santacruz, isso é uma armadilha, que abre possibilidades para a corrupção e criminalização local, já que as pessoas ocupando esses cargos não tinham formação, conhecimentos nem estruturas administrativas de respaldo para operar com dinheiros estatais, dentro dos procedimentos burocráticos ditados pela lei. Com isso, o Criva entrou em crise. Seus dirigentes foram destituídos, as divisões dentro do resguardo aumentaram, as novas organizações tomaram o caráter de organizações zonais e ficou sob a responsabilidade de cada comunidade a administração dos recursos de transferências nacionais anuais.

Até o período analisado neste artigo o Criva existia como conselho regional e, à diferença das outras instâncias organizativas indígenas como as AATIs, ${ }^{4}$ as organizações zonais ou as comunidades, não contava com dinheiros públicos para se sustentar e dependia inteiramente de projetos e de financiamento externo. Até 2014 existia como conselho regional, que afiliava várias comunidades do resguardo (não todas) e atuava como interlocutor da Opiac na região, mas somente com funções políticas de consulta, divulgação e comunicação, sem representatividade jurídica.

No final de 2014 a existência e as competências do Criva estavam de novo em revisão. Alguns dos antigos membros e fundadores propuseram outra forma de organização regional, que substituiria o Criva e recuperaria a representação

4 A AATI significa Associação de Autoridades Tradicionais Indígenas, cujas características serão explicadas mais adiante. 
e administração dos dinheiros do resguardo e a representatividade do departamento como um todo. Dessas negociações, junto com mudanças nacionais, surgiu posteriormente o Conselho Maior do Vaupés, atualmente em funcionamento.

Nessa região cada povo, e entre eles cada clã, mantém autonomia; a autoridade de umas pessoas sobre outras é restrita, e até a formação do Criva não se encontravam estruturas nem noções de representatividade que permitissem a umas pessoas decidir por outras. Nesse contexto, as noções de coletividade e pertencimento marcadas pela Igreja foram fundamentais para construir um espaço político comum onde antes não existia uma noção de coletividade, e a ideia de "indígenas do Vaupés" cobrou um sentido abrangente que permitia reivindicar reconhecimento diante do Estado colombiano. Inclusive uma das novidades que trouxe essa primeira reunião do Criva foi juntar num mesmo tempo e lugar, e com objetivos comuns, pessoas e grupos que até esse momento se entendiam como inimigos ancestrais (Jackson, 1995).

A geração que depois foi conhecida como "velha guarda" do Criva teve seus primeiros anos de vida marcados pelos mesmos fatores que impulsam sua fundação: a educação com religiosos, em internatos, e a extração de borracha, atividade que as famílias faziam de modo sazonal. Isso possibilitou que além dessa construção de unidade indígena sobre um coletivo complexo e tenso de identidades diferenciadas, operasse também uma noção de vocação do trabalho comunitário: a entrega católica para uma comunidade vai se transformar no trabalho político desinteressado e, por isso mesmo, mais legítimo.

A construção desse espaço político teve outras influências do catolicismo; além de formas de agir e valores constitutivos mencionados, esteve também marcada por mudanças estimuladas nos modos de vida das populações, começando com os ataques feitos às malocas, e na insistência, quando não imposição, da moradia em casas, gerando uma nova forma do privado e do doméstico.

As malocas dos povos indígenas no noroeste amazônico são mais do que moradias, são sinônimos de grupos sociais. Eram o centro da organização social, econômica e cerimonial; lugar da vida cotidiana e ritual, de descanso e visitas, das cerimônias, do enterro dos mortos, do preparo da comida, e da elaboração da maioria dos artefatos de uso ritual e cotidiano.

A comida e o fogo são fundamentais na maloca. A comensalidade produz parentes não necessariamente feitos pela aliança nem pela descendência. 
Essa criação de vínculos é feita pelas mulheres e é parte central na criação da comunidade e na sua manutenção (Hugh-Jones, 2013). Consequentemente, essa prática é também política e é a condição de permanência das relações cotidianas, do equilíbrio que permite que a ordem comunitária se mantenha (Rossi, 2016, p. 140).

A mudança das malocas como residências coletivas para as comunidades como conjuntos de casas separadas, que podem ou não ter uma maloca como espaço coletivo (mas não residencial), teve várias consequências.

Primeiro, as malocas deixam de ser sinônimo do coletivo e deixam de ser o espaço cotidiano; segundo, o dia a dia passa a acontecer nas casas, criando um espaço do doméstico ou do privado, que se diferencia do espaço público e político, ainda que numa maloca essas categorias fossem inseparáveis e seu lugar fosse o mesmo; terceiro, se diferencia um espaço do público e do político, na construção de um centro comunitário, que em algumas comunidades toma a forma de uma maloca, contudo uma maloca em que não mora ninguém, que é centro de reuniões, lugar de acolhida de visitantes e espaço para celebração de rituais.

Essas novas malocas passam a ser o lugar de uma cultura ritualizada e masculinizada. Ritualizada por ser o espaço para os rituais e reuniões, e masculinizada porque dá prioridade às noções de etnicidade e conhecimentos transmitidos por vias masculinas e aos espaços políticos que, como será apresentado mais adiante, vão sendo cada vez mais masculinos, em diálogo com uma política nacional que é maioritariamente feita por homens.

Um quarto elemento a destacar nessa mudança seria que os espaços e práticas coletivas próprias das mulheres nas malocas, como os de produção de alimentos e comensalidade, vão para as casas familiares, deixam de ser coletivos e, nessa divisão espacial (antes não presente) entre público e o privado, localizam as mulheres, suas práticas e os domínios em que estas tinham incidência comunitária nesse novo espaço privado. Uma última mudança se refere ao cuidado das crianças, que antes era compartilhado entre várias pessoas na maloca, e agora passa a ser responsabilidade de cada núcleo familiar, e particularmente das mulheres, demandando sua presença constante.

A presença de religiosos na educação nos internatos também impactou as relações de gênero através de ensinamentos e nas relações que se estabeleciam de modo diferencial com padres e com freiras, que davam lugares a atribuições 
diferentes a homens e a mulheres indígenas. A primeira medida estava na diferença no controle da sexualidade de uns e outras. Nas rotinas no internato a separação entre homens e mulheres era obrigatória; mas os padres, à diferença das freiras, não tinham o mesmo cerco de mistério envolvendo seus corpos, e tiveram relações com mulheres indígenas e filhos na região.

Um exemplo desse cerco de mistério envolvendo as freiras aparece retratado em uma das conversas com Lucía, uma das mulheres dessa geração da velha guarda. Ela comentou a seguinte história de quando estava no internato:

As freiras eram muito estritas e misteriosas; sempre estavam muito vestidas, não podíamos tocar elas, não podíamos olhar para elas, tomavam banho escondidas. Então um dia, fomos ao porto atrás delas para ver como eram, se eram gente ou eram quê? E claro, eram pessoas, sim, mas gostavam de se esconder. Entanto estávamos vendo elas, outra freira nos encontrou e, que castigo que nos deram! (cf. Rossi, 2016, p. 318).

Para além do catolicismo, elementos próprios das relações entre os povos da região também foram determinantes. Um deles, que se sustenta até hoje, está nas tradições de hierarquia entre os diferentes grupos e dentro de cada povo. Para vários dos membros da velha guarda, homens e mulheres, a hierarquia tradicional está diretamente ligada à autoridade política e à legitimidade. Hierarquia que decorre das relações de parentesco, é herdada e transmitida pelos homens e mantida através de casamentos entre pessoas de grupos afins e hierarquias equivalentes.

Se participação está em relação com hierarquia, depende então de linhas de identificação masculinas e masculinizadas (Rossi, 2016), e para as mulheres, depende necessariamente de suas relações com homens: pais, irmãos e maridos. Tanto para homens quanto para mulheres, não se trata de um caráter de representatividade enquanto indígena em termos gerais, vem de um pertencimento específico e do respeito à hierarquia. Quer dizer, mais do que de uma unidade ou coletividade comum, vem do respeito a formas relacionais pautadas desde posições masculinas. Essa legitimidade dada pela posição étnica e pelo respeito aos princípios de hierarquia e parentesco constitui um capital simbólico para as lideranças chamadas da "velha guarda". As lideranças das próximas gerações vão ter outros capitais, como a formação acadêmica 
ou universitária, as relações com entidades públicas ou ONGs, e as inserções no mercado de trabalho.

Nos registros da reunião de formação do Criva constam cinco mulheres nas delegações oficiais. Todas são professoras ou alfabetizadoras. No entanto, essas listas só incluem representantes das sete delegações do departamento, não de todos os participantes.

\section{Resguardos indígenas no Vaupés}

Na legislação colombiana, o resguardo como figura de propriedade coletiva da terra tem sua origem na colônia espanhola, e nunca foi totalmente desmantelada. A recuperação dos resguardos que tinham sido eliminados foi uma das lutas políticas dos indígenas na primeira metade do século XX, e é somente a partir da lei 135 de 1961, lei da reforma agrária, que foi possível criar novos resguardos (Pineda Camacho, 2016). Todos os resguardos no Vaupés foram criados nesse marco.

De acordo com a constituição colombiana (República de Colombia, 1991, art. $286,287,329)$ os territórios indígenas reconhecidos como resguardos são entidades territoriais indígenas com autonomia para gestão de seus interesses. São de propriedade coletiva, inalienáveis, e têm o direito de se governar por autoridades próprias, administrar o dinheiro que o governo central transfere (a todas as entidades territoriais do país) através do sistema geral de participações (SGP) e estabelecer os tributos necessários para o cumprimento de suas funções.

A propriedade coletiva sobre o território é uma das maiores conquistas dos povos indígenas na Colômbia, como garantia sobre a qual podem ser reivindicados a maioria dos outros direitos e reconhecimentos legais. Opera como a base para a autonomia para se governar e nas relações entre a institucionalidade do Estado colombiano e as autoridades indígenas.

No departamento do Vaupés há três resguardos indígenas: o Resguardo Parte Oriental do Vaupés, o Resguardo Bacatí Arara, e o Resguardo - Parque Natural Yaigojé - Apaporis.

O Resguardo Vaupés foi estabelecido em 1982, nove anos depois da constituição do Criva, mediante a resolução 086 do Instituto Colombiano de Reforma Agrária (Incora), cobrindo uma área de 3.354 .097 hectares. Sua administração 
depende parcialmente da prefeitura de Mitú, e parcialmente da governação do departamento. Está dividido internamente em organizações zonais indígenas e Associações de Autoridades Tradicionais Indígenas (AATIs), e cada organização agrupa comunidades de uma ou várias etnias. Segundo o censo nacional de 2005, tinha uma população de 17.109 pessoas, e estimava-se que até o ano de 2010 teria 17.670 habitantes (Departamento Administrativo Nacional de Estadística, 2014). Segundo comunicação pessoal de funcionários da governação em 2013, teria nesse ano 15.377. A diferença nos números de população reflete disparidades nos registros em função da entidade encarregada, os meios e momentos em que se fazem e os objetivos de cada contagem. Essas cifras operam simultaneamente no exercício da administração pública, sem que sejam unificados esses dados populacionais.

\section{Administração do Grande Resguardo Vaupés}

Na legislação colombiana, as autoridades dos resguardos indígenas são autoridades públicas de caráter especial, e como tais devem participar na formulação e adequação de políticas regionais e locais, especialmente em assuntos de ordenamento territorial, saúde, educação e infraestrutura. Devem fazê-lo em coordenação com a autoridade encarregada da zona na qual está seu território, mediante mecanismos de representação, consulta e negociação.

A descentralização da administração do Estado colombiano, cujas bases estão na Constituição de 1991, previa um reordenamento da administração territorial que ainda não foi concluído. Os resguardos indígenas passariam a ser Entidades Territoriais Especiais, mas como a lei que regulamenta seu funcionamento ainda não foi aprovada, são administrados num regime de transição.

Desde 1994 o Resguardo Vaupés recebe transferências do orçamento nacional. Segundo a lei 60 de 1993 (República de Colombia, 1993a), o valor destinado pelo governo nacional aos resguardos é proporcional à população declarada dentro de seus territórios e transferido anualmente, sendo atribuído a cada comunidade. Para o caso das comunidades administradas sob a forma de organizações zonais no Vaupés, o gasto dos recursos se faz através da prefeitura de Mitú ou da governação do departamento (Departamento Administrativo Nacional de Estadística, 2007, p. 15). Para a administração desse orçamento, segundo 
conversas com funcionários da prefeitura de Mitú em 2013, eram usadas cifras do censo de 1995, e dos censos feitos dentro de cada comunidade pelos capitães.

Os resguardos do Vaupés estão divididos internamente em organizações de diferentes tipos: Organizações Zonais e AATIs, cujos presidentes são autoridades encarregadas da representação e do contato com o governo colombiano e departamental. Cada organização agrupa comunidades ${ }^{5}$ de uma ou várias etnias, e cada comunidade é, legalmente, o núcleo administrativo mínimo perante o governo colombiano, representado por um capitão (Salazar; Gutiérrez; Franco, 2006, p. 58).

As Associações de Autoridades Tradicionais e Capitães Indígenas são uma figura jurídica de transição à espera da regulamentação das Entidades Territoriais Indígenas (ETIs), proposta em 1991 e à espera de uma Lei Orgânica de Ordenamento Territorial. Enquanto isso não acontece, foi expedido o decreto 1088 de 1993 (República de Colombia, 1993b), que cria a figura das AATIs para se "associar, participar e fortalecer seu desenvolvimento econômico, social e cultural". São entidades de direito público e de caráter especial; pessoas jurídicas com patrimônio próprio e autonomia administrativa, e podem executar diretamente, de forma total ou parcial, a verba transferida pelo orçamento nacional (República de Colombia, 1993b, art. 3).

No caso das Organizações Zonais, em termos administrativos, a gestão do dinheiro de transferências orçamentais do Estado é feita de maneira separada por cada comunidade e com a intermediação da autoridade territorial competente (prefeitura de Mitú ou governo do Vaupés). Isso reduz a margem de ação da organização e assim as possibilidades de investimentos de longo ou médio prazo (já que divide a verba em pequenas porções e em orçamentos anuais, não acumuláveis), e faz mais trabalhosa a administração municipal, que deve gerir projetos particulares para cada comunidade.

Como parte das mudanças organizativas e das reestruturações políticas pós-Constituição, nos anos 2000 várias zonais foram desfeitas para constituir novas organizações ou para se transformar diretamente em AATIs. Nesse marco administrativo, a identidade indígena está claramente incorporada em um Estado envolvente, em termos onde o reconhecimento dessa diferença

5 "Comunidade" é o termo estabelecido na lei e utilizado cotidianamente para o que no Brasil seria chamado de "aldeia". 
implica necessariamente o reconhecimento da existência e autoridade indígenas. No entanto, o funcionamento prático do exercício dessa autoridade inverte os termos da adaptação: no discurso, a política deve reconhecer e se adaptar às diferenças e particularidades; na administração do resguardo, as autoridades devem reconhecer a forma de funcionamento do Estado, e se adaptar às suas formas de operar. A estrutura do Criva já não dialogava com essas formas políticas e administrativas.

É interessante comparar o caráter burocrático dessas relações com o tipo ideal de burocracia descrito por Weber, para pensar sobre as particularidades de seu funcionamento. Os processos de burocratização descritos por Weber são configurações específicas de funcionamento que vão se constituindo até se converter em sistemas estáveis que se autorreproduzem e tendem a se manter. Seriam processos nos quais a dominação é convertida em rotina, em algo disperso que se converte em administração cotidiana (Weber, 1974, p. 249). Todas essas formas de operação fazem parte das relações entre as organizações indígenas e as instituições estatais, materializadas em documentos, arquivos, procedimentos, atores, entidades, prazos e normas que fazem complexos e difusos o reconhecimento da identidade coletiva e o exercício desses direitos coletivos estabelecidos.

A burocratização das relações opera mais entre autoridades indígenas e os organismos do Estado do que dentro das organizações, e a estabilidade que Weber menciona se dá na forma que tomam esses relacionamentos, mas não nas organizações indígenas, o que obedece, provavelmente, à falta de condições materiais para o exercício dos direitos, o que implica, entre outras coisas, que as autoridades indígenas, inclusive aquelas que teriam a mesma condição jurídica que prefeitos ou governadores, não tenham salário, condição que está sustentada numa contradição.

São autoridades definidas pela lei como "internas", sendo assumido que terão um reconhecimento igualmente "interno" pelo seu trabalho, e que têm um caráter atemporal, quer dizer, que sempre estiveram aí exercendo autoridade, e agora a mudança seria somente que o Estado colombiano as reconhece como tais, e como interlocutores relevantes (naturalizando, assim, os efeitos do exercício de poder, e apagando o processo de constituição dessas autoridades). Em consequência, não são estritamente funcionários públicos pagos pelo orçamento nacional, mas autoridades públicas de caráter "especial". Mas a contradição está 
em que são autoridades públicas definidas pela lei colombiana, criadas por ela e trabalhando em função da interação com a administração do Estado.

\section{Participação política depois da década de 1990}

A década de 1990 trouxe mudanças para todo o departamento, começando com o artigo 309 da Constituição, pelo qual o Vaupés muda sua condição dentro do país, passando de ser comisaría a ser departamento. A reorganização administrativa nacional foi se implementando nessa década, e entre suas consequências estava uma maior autonomia em seu governo, e o início das eleições populares de governação e prefeitura, que começaram em 1997. Antes das primeiras eleições, Mitú teve seu primeiro prefeito indígena, nomeado desde a presidência da república, Maximiliano Veloz, que exerceu seu mandato desde 1993, mas se demitiu do cargo antes de terminar o período, em resposta a mobilizações indígenas que pediram sua demissão em 1994.

Em outras regiões do país que passaram pela mesma mudança administrativa houve eleições em 1993, mas aqui o território não estava considerado sob controle do Estado, mas em disputa entre forças associadas ao tráfico de cocaína e à presença forte das Forças Armadas Revolucionárias da Colômbia (Farc).

Isso marca o período: o conflito armado na região, concretamente os enfrentamentos entre as Farc e o exército colombiano, mais acirrados entre 1988 e 2005. Em 1988 aconteceu a primeira ofensiva à cidade de Mitú por parte das Farc, que atacaram o quartel da polícia. Dez anos depois, em novembro de 1998, aconteceu a segunda tomada da cidade por parte dessa guerrilha. Depois de três dias a cidade foi retomada pelo exército. Depois da retomada da cidade, os enfrentamentos continuaram, especialmente na zona da estrada Mitú-Montfort, e na zona do resguardo atravessando o rio Vaupés, na frente da cidade. Mais ou menos por volta de 2005 poderia ser dito que a região da cidade passou a ser controlada pelo exército, que continuou seus avanços no território, até que depois de 2013 adquiriu controle no médio e alto rio Vaupés, fazendo com que novamente pudesse ser transportada carga pelo rio, desde o departamento de Guaviare, até Mitú.

Ainda antes da segunda tomada o espaço público era um lugar de participação viável para a população; nos anos 1990 foram depostos um prefeito 
e um governador por movimentos de pressão popular, liderados em sua maioria por indígenas. Mas depois da segunda tomada, em 1998, não houve mais mobilizações desse porte. Esses enfrentamentos armados trouxeram o medo como parte das condições do cotidiano e do político, e geraram conflitos nas comunidades e nas organizações cujos territórios foram mais afetados, fraturando vínculos de confiança, deslocando populações e estabelecendo práticas de silêncio e dissímulo que antes não estavam presentes. Com isso algumas lideranças da velha guarda foram deixando seu protagonismo, diminuíram os impulsos para grandes reuniões, e participar politicamente começou a ser lido também como perigoso, como já acontecia em outros lugares da Colômbia.

Mas também surgiram espaços novos; desde os anos 1990 começou a ser obrigatória a participação das mulheres indígenas, o que se materializou na criação das "áreas de mulher" e o cargo de representante para coordenar essas áreas dentro das organizações. Também foi sendo mais técnica e burocratizada a participação e as negociações com o Estado e com ONGs de várias escalas. Isso ofereceu possibilidades interessantes de organização e gestão, mas exigiu novas capacidades técnicas, lideranças com níveis de formação mais alta e renovação de alguns cargos. A política passou a ser um espaço de gestão, administração e representação, e progressivamente vão se cristalizando algumas representações do que era a política indígena antes desse momento.

Essa cristalização está marcada por uma visão um pouco saudosa do surgimento do movimento indígena na Colômbia. As noções de trabalho comunitário, de entrega e de unidade são acionadas para definir esse momento, e estão baseadas nas formas cristãs de fazer política, em relação com a educação católica recebida pelas pessoas dessa primeira geração e com a presença fundadora da Igreja nos movimentos.

Como já foi mencionado, essa articulação entre política e Igreja também acompanha uma nova distribuição das relações de gênero e dos lugares de homens e mulheres na política e nos espaços domésticos das casas, recentes e também ligados à ação missionária. $\mathrm{O}$ espaço de participação política vai virando masculino e a casa vai se consolidando como moradia, espaço doméstico e domínio feminino, em oposição às malocas como residências comunitárias e multifamiliares, cotidianas e rituais, cada vez menos frequentes no departamento.

A partir da década de 1990, começa a ganhar destaque nas organizações, e nas suas novas áreas de mulher, o discurso da mulher como centro da família 
e como transmissora da cultura, recrudescendo a associação do feminino a essa esfera privada, recém-criada. Mas esse é também um discurso católico do lugar moral da mulher na religião e na casa, possível porque a cena política foi construída com repertórios discursivos e de ação católicos. A mulher como transmissora da cultura não se relaciona nem com as formas em que os grupos de descendência são pensados, representados e reproduzidos, nem com as alternativas das mulheres para construir lugares de reconhecimento dentro deles. O exercício da participação política passa por reuniões em diferentes lugares dentro e fora do país e atividades de formação e negociação, todas elas demandando recorrentes e por vezes longos períodos fora da casa. Dessas novas casas que viraram espaço e responsabilidade das mulheres, assim, se ausentar agora é mais oneroso para elas.

Já nos anos 2000 a nova geração de mulheres dentro das organizações do resguardo se depara com o fato de que a participação política marcada pela etnicidade está configurada como um domínio masculino e, nela, participar se oferece como uma oportunidade de mobilidade social pela via da mudança de lugares de gênero. Essa nova configuração está marcada, entre outras coisas, pela obrigatoriedade de incluir "mulheres", "gênero" e "equidade" nas políticas públicas, nos projetos de cooperação internacional e dentro das estruturas de governo e representação indígena.

\section{Reconfigurações dos lugares das mulheres no repertório da política etnicamente diferenciada}

Apresento essas reconfigurações a partir de duas situações distintas: a campanha política de uma candidata indígena à Câmara Nacional de Representantes, em 2014; e a realização de dois encontros de mulheres indígenas, de duas organizações distintas, entre 2013 e 2014.

A candidata que analisaremos, Clara Santacruz, é uma mulher wanana, que construiu sua campanha reivindicando legitimidade por ser indígena, falar sua língua e ser oriunda da região. Ela tinha 40 anos em 2014. Se apresentava como candidata em nome de 24 povos indígenas do departamento do Vaupés. Para ela, a origem do seu clã entre os Wanano e sua hierarquia são especialmente relevantes para reivindicar lugares políticos. 
A primeira vez que encontrei Clara, já em campanha política, foi em um dos encontros de mulheres que serão apresentados, em janeiro de 2014 na comunidade de Pituna. Nesse encontro, a representante da área de mulher fez um acordo com vários candidatos: cada um iria um dia para apresentar sua proposta de campanha e, em troca, se comprometeria a levar carne para o almoço de todos os presentes na reunião. Depois desse dia conversei com Clara com mais calma e marcamos uma outra conversa, que foi mais detalhada. Clara começou sua participação na década de 1990; assume como dada a discriminação das mulheres na participação política e reivindica os espaços femininos em termos católicos, a mulher como centro do lar e da vida, com relação a uma noção de casa, entendida já não como a maloca nem como a residência da família extensa, mas como a unidade doméstica do casal e seus filhos. Esse lugar da mulher na política enquanto companheira do homem, do mesmo modo que seria a companheira dele no lar, não vai fazer parte do discurso das mulheres da geração anterior, mas faz parte do momento em que Clara começa a participar, no qual já é frequente considerar a política como um espaço masculino e a participação feminina como um gesto pessoal de se abrir caminhos novos, no qual ser mulher vira um lugar de enunciação relevante.

A oposição entre gerações vai ser recorrente no seu discurso; os que se consideram velhos ou lideranças "com trajetória" falando que as lideranças atuais trabalham por interesses individuais, que não têm mística, não se esforçam e não entendem realmente as necessidades indígenas por terem sido formados "fora". Isso vai contrastar com os jovens falando que as velhas gerações não soltam o poder, que têm vícios, que não deixam que as coisas passem para as novas gerações. Clara se encontra no meio caminho entre a velha guarda e as novas gerações. Sua trajetória se parece mais com a da primeira geração, formada por religiosos e trabalhando como professora no departamento; seu marido faz parte dessa velha guarda, mas o momento em que ela começa a fazer parte da política já é depois da Constituição de 1991, da transferência de dinheiro público às comunidades e no início da profissionalização desses cargos.

A linguagem dos direitos, especificamente "os direitos dos povos", constitui para Clara um marco de referência. Também aparece, de um lado, o espaço público-político como distante das mulheres, que não contam com os mesmos níveis de formação que os homens, até ser um espaço alheio; e do outro lado uma feminização da casa, e um conjunto de obrigações com a família 
e os filhos, que são femininas e impedem a mulher de se ausentar, o que antes não aparecia na fala de mulheres da "velha guarda". Isso entra em conflito com a ideia dos espaços femininos "tradicionais": esses espaços que se referem à vida em malocas, mas vão se diluir nas comunidades de casas unifamiliares.

Em seu discurso o território opera como sustento moral para reivindicar pertencimento, o que demanda atenção. Independentemente de que o território e o discurso sobre ele sejam repertórios masculinos, no momento em que Clara inicia sua trajetória política o resguardo é uma categoria territorial política e administrativa consolidada; há três resguardos no departamento e a administração pública deles já está em mãos das organizações indígenas. Esse lugar de interlocução política diante o governo não é dado por ser de um povo ou outro; é dado pelo resguardo como entidade diferenciada, e a representatividade das organizações que dentro dele surgem é dada também em termos de população e território. O território do qual ela fala, o que pretende representar e o que lhe daria legitimidade, não é narrado na chave de lugar de origem de seu povo, nem de narrações míticas ou descendência de povos do Vaupés; é o território reconhecido pela lei, propriedade coletiva e administrável através de práticas profissionais e burocráticas nas quais ela é plenamente competente e legítima. Os novos saberes associados a esse território são suscetíveis de virar saberes femininos também.

Passamos agora à segunda situação de análise. Entre 2013 e 2014 acompanhei dois encontros de mulheres indígenas, da Organização Zonal Central Indígena de Mitú (Ozcimi) e da União de Indígenas Cubeo do Igarapé Cuduyarí (Udic). ${ }^{6}$ As duas organizações têm histórias, formas de funcionamento e composições de população diferentes, na localização das comunidades, suas condições de acesso a recursos e seus pertencimentos étnicos. No entanto as reuniões tiveram muitos elementos comuns.

6 A Ozcimi foi constituída em 1992 e registrada em 1995. Reunia, em 2008, 18 comunidades localizadas nas margens do rio Vaupés nas imediações de Mitú, e algumas ao redor da estrada Mitú-Montfort, mais a população indígena da cidade de Mitú (Organización Zona Central Indígena de Mitú, 2008, p. 5). A Udic nasceu em 1975; quase 20 anos depois se converte em uma organização zonal, no fim de 1994, com o nome de União de Indígenas Cubeo do Igarapé Cuduyarí, agora dentro do resguardo Vaupés. Reúne em seu território as 21 comunidades que ocupam as ribeiras do igarapé Cuduyarí e que são autorreconhecidas como cubeas (Unión de Indígenas Cubeo del Cuduyari, 2009, p. 15, 16). Em 2014 mudou sua condição legal para se converter em AATI, com o nome Associação Pamijavoba Udic. 
O encontro da Ozcimi foi realizado na comunidade de Tucandira, durante três dias em novembro de 2013, proposto pela representante titular das mulheres da organização e apoiado pela suplente. Para seu planejamento contou com o apoio da capitã de uma das comunidades localizadas na beira do rio. Participaram 36 pessoas, em sua maioria mulheres, das etnias Desana, Cubeo, Siriano, Carapana, Wanano, Bara, Tuyuca, Huitoto; e as representantes da área de mulher, sem presença de outras das diretivas da organização. Foi desenvolvido em espanhol, língua falada por todos os presentes.

O encontro da Udic foi realizado na comunidade de Pituna, no médio igarapé Cuduyarí, durante quatro dias consecutivos. Participaram 63 pessoas e foi mais formal que o de Tucandira. Nele participou o presidente da zonal, na abertura e fechamento do evento, representantes da Opiac e profissionais contratados por essa organização se encarregaram de parte das atividades. Foi desenvolvido mais da metade do tempo em espanhol, com traduções para o Cubeo. Teve momentos em que foi só em Cubeo, e nem sempre com tradução para o espanhol. Os funcionários convidados para o evento não falavam Cubeo, situação compartilhada por poucas das mulheres membros da Udic. Em ambos os encontros foi visível a existência de dois discursos sobre as mulheres indígenas, entendidas como coletivo geral. Um discurso falava das mulheres como centro da cultura, como meio privilegiado para sua transmissão (o que se opõe ao sistema de parentesco e pertencimento mencionado) e como trabalhadoras fundamentais na roça e na casa. Esse discurso foi enunciado por homens e mulheres em diferentes momentos nos dois eventos e não foi questionado. $O$ outro discurso tinha a ver com a participação política, a necessidade de envolver mais mulheres, de as capacitar para a participação e de ampliar sua presença política. Esse discurso também foi enunciado por homens e mulheres em diferentes momentos nos dois eventos, e também passou sem ser questionado, ao contrário, foi eixo para a construção de planos futuros.

A ênfase dada ao trabalho da roça e da casa como femininos e como marcadores da identidade das mulheres indígenas contrasta com o lugar que se espera alcançar depois das capacitações desejadas em formas de produção não agrícola, educação universitária e formação política, quer dizer, com os lugares que as mulheres começam a ocupar através da participação nesses espaços público-políticos masculinizados. 
Às divisões de funções de autoridade e comunicação entre estes povos, e de transmissão da identidade pela via masculina, se soma a forte presença da Igreja no processo. Posteriormente, os requerimentos de formação associados a esses espaços, e os maiores níveis de educação escolar dos homens com relação aos das mulheres reforçaram ainda mais o protagonismo masculino nesse espaço. Paralelamente, os discursos da etnicidade como base para a participação política, já presentes na década de 1980 e mais destacados a partir de 1990, são baseados em pertencimentos, grupos de descendência e saberes transmitidos por vias masculinas e narrados por homens. Todas essas características reforçam que a participação política seja maioritariamente de homens no Vaupés, o que se conjuga com a política regional e nacional, que depois da Constituição fez da mulher um assunto obrigatório dentro das organizações, seguindo diretrizes nacionais e internacionais sobre gênero e participação política que pretendiam ampliar a participação feminina, e cristalizou assim representações e formas de operação desses espaços como masculinas.

Voltando aos encontros dos quais participei, não pretendo apresentar a confluência desses dois discursos como contraditória sem mais; sugiro pelo contrário que ela reflete uma compreensão do funcionamento do Estado nas suas aparentes contradições, que aqui se fazem presentes na simultaneidade de narrativas sobre a identidade indígena, o reconhecimento e a participação, e sugiro pensá-la à luz da proposta de Veena Das sobre o paradoxo da ilegibilidade do Estado.

A administração e a participação política no resguardo podem ser pensadas à luz da noção de margens do Estado como os lugares onde este não é evidentemente legível; e como os espaços nos quais as relações entre corpos, leis e disciplinas se fazem mais evidentes (Das; Poole, 2004, p. 9-10). Justamente por esse caráter marginal o papel das práticas de participação política resulta tão interessante para pensar na constituição de corpos generificados, e marcados pela etnicidade, em um contexto de múltiplas fronteiras de pertencimento.

Segundo Das, o caráter escrito do funcionamento do Estado e de suas formas burocráticas lhe dá um traço de iterabilidade, ${ }^{7}$ no qual a repetição de fragmentos é uma possibilidade gerada a partir do registro escrito, e que implica

7 A noção de iterability é tomada pela autora de Derrida, que tira o R de reiterability, de reiterar. 
a possibilidade de repetir exatamente o mesmo, ou quase, mas em outro contexto ou de outro modo. Já aquele "outro contexto" implica que o exercício não pode ser exatamente o mesmo; que necessariamente as mesmas palavras não vão significar as mesmas coisas. Nessa repetição haverá, ademais, um elemento de surpresa, algo imprevisível no caráter contingente de qualquer enunciação. Esse assunto de transformar mediante a repetição é o que faz o Estado aparentemente ilegível (Das, 2004, p. 226-227).

Desde essa leitura da repetição que modifica os sentidos, não existe uma incoerência em frases como: "a mulher que vale é a que tem roça", mas sim uma ilegibilidade nessa frase quando está sendo enunciada por mulheres indígenas que estão pedindo novos espaços de educação ou trabalho que lhes permitam sustentar suas famílias sem trabalhar na roça. Seguindo o caminho de repetições dessa frase, encontramos que faz parte de reivindicações sustentadas numa representação de etnicidade que se expressa num espaço político que constrói o trabalho na roça como emblemático da mulher indígena, especificamente da mulher indígena "que vale". Então não só deixa de ser incoerente, mas passa a ser necessário reivindicar o valor moral da mulher indígena em função do seu trabalho na roça, como caminho prático para buscar num espaço público e político alternativas diferentes a esse tipo de trabalho, e nas quais sua identidade étnica continue sendo prioritária, tanto como elemento íntimo de identificação pessoal quanto como garantia social de reconhecimento e condição jurídica de seus direitos.

Outro elemento sobre o qual chamo a atenção é o lugar do território nos discursos femininos. O território como lugar de origem dos povos faz parte dos conhecimentos e discursos masculinos, transmitidos por via paterna, como a filiação, e enunciados por homens. Não corresponde às mulheres transmitir a filiação étnica, nem os conhecimentos associados a ela, o conhecimento do território não lhes pertence. No entanto, nas enunciações políticas das mulheres, tanto em reuniões quanto em outros cenários de política eleitoral, o território é central como base para as reivindicações, fonte de legitimidade, e sustento a ser representado, protegido e administrado. Esse território é o Vaupés, a floresta amazônica, o resguardo, as comunidades. Marcados sim por pertencimentos e identificações indígenas, mas não em termos de origem mítica nem de propriedade de etnias ou clãs. Esse território como referente genérico se faz possível pelo reconhecimento jurídico dos resguardos, e nessa medida passa 
a ser suscetível de ser capital político das mulheres. O território legalmente reconhecido dá ferramentas de participação política às mulheres, no mesmo cenário em que cria esse espaço político masculinizado.

É nesse espaço de aparente ilegibilidade que as relações de gênero recuperam as mudanças nos sentidos do território enquanto propriedade coletiva e referente identitário indígena, e se valem delas para reconfigurar as possibilidades femininas de representação e participação política, e com isso incidem em formas de mobilidade social e atualizações da etnicidade feminina.

\section{Gênero e etnicidade nos repertórios de participação política}

Os processos de construção e mudanças das relações de gênero, das possibilidades pessoais e íntimas de identificação e de construção de relações, pertencimentos e coletividades, têm consequências nos espaços de representação e participação política, nos quais as dimensões íntimas da etnicidade se articulam com práticas de organização e de representação, com várias profundidades históricas, com as quais as mulheres se pensam, atuam e procuram construir espaços de acolhimento, de representação e de mudanças. Essa junção de várias dimensões constitui um repertório de possibilidades para a ação individual e política e para a gestão feminina da etnicidade.

Este artigo discute um processo recente de criação e modificação de um espaço político de interlocução com o Estado colombiano que está marcado pelo reconhecimento da diferenciação étnica e das construções e representações das relações de gênero e especificamente do feminino. Trata-se da construção de um espaço e um repertório do político que trazem consigo uma transformação nas relações de gênero e nas representações sobre as mulheres indígenas de modo geral. Mas é preciso salientar que não é só a participação das mulheres indígenas a que se constrói nesse processo, o Estado colombiano como pluriétnico e multicultural também se constrói nesses movimentos, e várias formas de administração e governo de populações e territórios tomam forma, são disputadas e se materializam nessas relações.

Como foi mencionado, para as mulheres indígenas do Vaupés, a identidade, 0 pertencimento e a convivência são diferentes. Mas, como já apresentei em outro contexto, as mulheres se identificam com os grupos de descendência masculina 
que são sustento das divisões entre pertencimentos étnicos, e não sugerem outras representações de etnicidade nem de parentesco que questionem essa ordem. Não haveria outra versão, feminina, das narrativas de identidade; mas isso não significa que as mulheres se reconheçam, sem mais, nessas narrativas que as localizam como estrangeiras ou ausentes (Rossi, 2016, p. 371-372).

O reconhecimento acontece em vários reposicionamentos que se fazem com relação aos diferentes grupos de possíveis identificações. Os referenciais de família, clã, língua, grupo exogâmico, grupo étnico, indígenas, amazônicos, colombianos ou brasileiros operam como categorias de maior ou menor abrangência, e o que fica nas margens de uma delas pode entrar plenamente em outra. A acumulação dessas categorias na vida diária e nos espaços políticos permite e exige seu agenciamento.

Recuperando o que foi mencionado no início sobre como essas fronteiras étnicas se localizariam nos corpos das mulheres, sua participação política, que leva como eixo a etnicidade, faz uma desestabilização dessas diferenciações, colocando o reconhecimento do pleno pertencimento das mulheres como condição - e como consequência - desse exercício e essa reivindicação de direitos coletivos.

Nesse cenário complexo, a propriedade coletiva do território como direito (e atributo) associado à etnicidade, e despojado das linhas de transmissão e propriedade masculina, transforma as possibilidades de legitimidade e representatividade política femininas, e amplia seu repertório, sem que por isso precise de oposição ou contradição, mas dentro das articulações complexas e sempre circunstanciais das diferentes escalas de relação, identificação e reconhecimentos com as quais essas identidades são construídas e vivenciadas.

\section{Referências}

CABRERA BECERRA, G. El Geral y la colonización en el Alto Río Negro-Vaupés. In: CHAVES, M.; CAIRO, C. del. (comp.). Perspectivas antropológicas sobre la Amazonia contemporánea. Bogotá: Instituto Colombiano de Antropología e Historia, 2010. p.365-390.

CORREA, F. Indígenas horticultores del Vaupés. In: INTRODUCCIÓN a la Colombia Ameríndia. Bogotá: Ministerio de Educación Nacional: Instituto Colombiano de Cultura: Instituto Colombiano de Antropología: Editorial Presencia, 1987. p. 113-130. 
CORREA, F. Por el camino de la Anaconda Remedio: dinámica de la organización social entre los Taiwano del Vaupés. Bogotá: Universidad Nacional de Colombia: Colciencias. 1996.

DAS, V. The signature of the state: the paradox of illegibility. In: DAS, V.; POOLE, D. Anthropology in the margins of the state. Santa Fe: School of American Research Press, 2004. p. 225-252.

DAS, V.; POOLE, D. State and its margins. Comparative ethnographies. In: DAS, V.; POOLE, D. Anthropology in the margins of the state. Santa Fe: School of American Research Press, 2004. p. 3-33.

DEPARTAMENTO ADMINISTRATIVO NACIONAL DE ESTADÍSTICA (DANE). Colombia: una nación multicultural: su diversidad étnica. Bogotá, 2007.

DEPARTAMENTO ADMINISTRATIVO NACIONAL DE ESTADÍSTICA (DANE). Proyecciones de población indígena en resguardos a junio de 2014. Bogotá, 2014.

HUGH-JONES, C. Desde el río de leche: procesos espaciales y temporales en la Amazonia noroccidental. Bogotá: Ediciones Universidad Central, 2013.

JACKSON, J. E. Vaupés marriage: a network system in the Northwest Amazon. In: SMITH, C. (ed.). Regional analysis: vol. II: social systems. New York: Academic Press, 1976. p. 65-93.

JACKSON, J. E. Culture, genuine and spurious: the politics of indianness in the Vaupés, Colombia. American Ethnologist, v. 22, n. 1, p. 3-27, 1995.

JACKSON, J. E. Treinta años estudiando el Vaupés: lecciones y reflexiones. In: FRANKY, C. E.; ZÁRATE, C. G. (ed.). Imani mundo: estudios en la Amazonía colombiana. Leticia: Universidad Nacional de Colombia: Instituto Amazónico de Investigaciones Imani, 2001. p. 373-395.

ORGANIZACIÓN ZONA CENTRAL INDÍGENA DE MITÚ (OZCIMI). Plan integral de vida indígena. Mitú, 2008.

PINEDA CAMACHO, R. Estado y pueblos indígenas en el siglo XX. La política indigenista entre 1886 y 1991. Revista Credencial Historia, oct. 2016. Disponível em: http:// www.revistacredencial.com/credencial/historia/temas/estado-y-pueblos-indigenas-en-el-siglo-xix. Acesso em: 20 set. 2019.

REPÚBLICA DE COLOMBIA. Constitución política de Colombia. Bogotá, 1991.

REPÚBLICA DE COLOMBIA. Congreso de la República. Ley 60 de 1993. Bogotá, 1993 a. 
REPÚBliCA DE COLOMBIA. Presidencia de la República. Decreto 1088 de 1993. Bogotá, 1993b.

REPÚBLICA DE COLOMBIA. Ministerio del Interior. Decreto 632 del 10 de abril de 2018. Bogotá, 2018.

ROSSI, M. Identidade sem pertencimento?: dimensões íntimas da etnicidade feminina no Vaupés. 2016. Tese (Doutorado em Antropologia Social) - Museu Nacional, Universidade Federal de Rio de Janeiro, Rio de Janeiro, 2016.

SALAZAR, C. A; GUTIÉRREZ, F.; FRANCO, M. Vaupés: entre la colonización y las fronteras. Bogotá: Instituto Amazónico de Investigaciones Científicas SINCHI, 2006.

SANTACRUZ, J. Principios fundamentales del Consejo Regional Indígena del Vaupés. Mitú: Comisaría Especial del Vaupés, 1985.

SCOTT, J. Gender: a useful category of historical analyses. In: SCOTT, J. Gender and the politics of history. New York: Columbia University Press, 1988. p. 25-50.

TEIXEIRA, C. C.; SOUZA LIMA, A. C. de. A antropologia da administração e da governança no Brasil: área temática ou ponto de dispersão?. In: DUARTE, L. F. D.; MARTINS, C. B. (org.). Horizontes das ciências sociais no Brasil: antropologia. São Paulo: Anpocs, 2010. p. 51-95.

TROUILLOT, M.-R. The anthropology of the state in the age of globalization. Close encounters of the deceptive kind. Current Anthropology, v. 42, n. 1, p. 125-138, 2001.

UNIÓN DE INDÍGENAS CUBEO DEL CUDUYARI (UDIC). Plan integral de vida indígena del Pueblo Cubeo - Zonal UDIC. Mitú, 2009.

VIANNA, A.; LOWENKRON, L. O duplo fazer do gênero e do Estado: interconexões, materialidades e linguagens. Cadernos Pagu, Campinas, n. 51, e175101, 2017.

WEBER, M. Burocracia. In: WEBER, M. Ensaios de sociologia. Rio de Janeiro: Zahar, 1974. p. 229-282.

Recebido: 30/09/2019 Aceito: 27/04/2020 | Received: 9/30/2019 Accepted: 4/27/2020 